\title{
Role of PKC $\varepsilon$ in the epithelial-mesenchymal transition induced by FGFR2 isoform switch
}

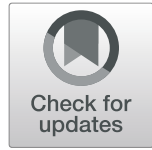

Danilo Ranieri ${ }^{1 \dagger}$, Monica Nanni ${ }^{1 \dagger}$, Flavia Persechino ${ }^{1}$, Maria Rosaria Torrisi ${ }^{1,2 \dagger}$ and Francesca Belleudi ${ }^{1 *+}$ (D)

\begin{abstract}
Background: The epithelial isoform of the fibroblast growth factor receptor 2 (FGFR2b) controls the entire program of keratinocyte differentiation via the sequential involvement of protein kinase $C$ (PKC) $\delta$ and PKCa. In contrast, the FGFR2 isoform switch and the aberrant expression of the mesenchymal FGFR2C isoform leads to impairment of differentiation, epithelial-mesenchymal transition (EMT) and tumorigenic features. Aim of our present study was to contribute in clarifying the complex network of signaling pathways involved in the FGFR2c-mediated oncogenic outcomes focusing on PKC , which appears to be involved in the induction of EMT and tumorigenesis in several epithelial contexts.
\end{abstract}

Methods: Biochemical and molecular analysis, as well as in vitro invasion assays, combined with the use of specific small interfering RNA (siRNA), were performed in human keratinocytes stably expressing FGFR2c or FGFR2b isoforms.

Results: Our results showed that aberrant expression and signaling of FGFR2C, but not those of FGFR2b, in human keratinocytes induced a strong phosphorylation/activation of PKC $\varepsilon$. The use of siRNA approach showed that PKC $\varepsilon$ is the hub signaling downstream FGFR2C responsible for the modulation of EMT markers and for the induction of the EMT-related transcription factors STAT3, Snail 1 and FRA1, as well as for the acquisition of the invasive behavior. Moreover, experiments of depletion of ESRP1, responsible for FGFR2 splicing in epithelial cells, indicated that the activation of PKC $\varepsilon$ is the key molecular event triggered by FGFR2 isoform switch and underlying EMT induction.

Conclusions: Overall, our results point to the identification of the downstream PKC isoform responsible for the FGFR signaling deregulation occurring in epithelial tissues from the physiological oncosoppressive to the pathological oncogenic profile.

Keywords: FGFR2C, PKCE, Epithelial-mesenchymal transition, Keratinocytes

\section{Background}

It is known that most of the human genes undergo alternative splicing and many studies have suggested that the isoform switch represent a crucial event in cancer [1]. In this regard, several studies have demonstrated that the

\footnotetext{
* Correspondence: francesca.belleudi@uniroma1.it

${ }^{\dagger}$ Danilo Ranieri, Monica Nanni, Maria Rosaria Torrisi and Francesca Belleudi contributed equally to this work.

'Department of Clinical and Molecular Medicine, Sapienza University of Rome, Laboratory Affiliated to Istituto Pasteur Italia - Fondazione Cenci Bolognetti, Viale Regina Elena 324, 00161 Rome, Italy

Full list of author information is available at the end of the article
}

switching from the epithelial isoforms of fibroblast growth factor receptors (FGFR1-3b) to the mesenchymal FGFR1-3c isoforms is frequently involved in epithelialmesenchymal transition (EMT) and cancer progression [2-4]. In the last years we focused our attention on the biological functions of the epithelial FGFR2b isoform, demonstrating that this receptor controls the entire program of keratinocyte differentiation [5-7] through the sequential involvement of $\mathrm{PKC} \delta$ and $\mathrm{PKC} \alpha$ signaling [7]. In contrast, we found that the FGFR2 isoform switch and the aberrant expression of the mesenchymal FGFR2c isoform in the same epidermal context induced

C The Author(s). 2020 Open Access This article is licensed under a Creative Commons Attribution 4.0 International License, which permits use, sharing, adaptation, distribution and reproduction in any medium or format, as long as you give appropriate credit to the original author(s) and the source, provide a link to the Creative Commons licence, and indicate if changes were made. The images or other third party material in this article are included in the article's Creative Commons licence, unless indicated otherwise in a credit line to the material. If material is not included in the article's Creative Commons licence and your intended use is not permitted by statutory regulation or exceeds the permitted use, you will need to obtain permission directly from the copyright holder. To view a copy of this licence, visit http://creativecommons.org/licenses/by/4.0/. The Creative Commons Public Domain Dedication waiver (http://creativecommons.org/publicdomain/zero/1.0/) applies to the data made available in this article, unless otherwise stated in a credit line to the data. 
changes in FGFR ligand specificity, leading to impairment of differentiation [8], EMT and early tumorigenic features $[9,10]$. In addition, we have also recently shown the negative impact of the out-of-context expression of FGFR2c on autophagy [11], consistent with a possible role of this receptor in the modulation of the proposed EMT/autophagy negative loop during carcinogenesis. However, although the multiple functional impacts of the aberrant expression of FGFR2c begin to be progressively described, the specific downstream signaling network underlying these oncogenic outcomes remain still to be identified. With the aim to contribute in dissecting this network, here we paid attention on PKCs. In particular, we focused on $\mathrm{PKC \varepsilon}$, which has been found overexpressed in several carcinomas, including squamous cell carcinomas (SCCs) [12, 13]. Moreover, PKCe shows the greatest oncogenic potential among PKC family members [13] and it has been proposed to play a relevant role in EMT induction [14, 15]: in fact, PKCe overexpression alone is sufficient to dramatically increase growth rate and motility in human keratinocytes (HKs) [16], as well as to induce EMT-related phenotype in non-tumorigenic mammary epithelial cells [14, 15], strongly encouraging us to go deeper inside on its possible function as key molecular player in the context of aberrant FGFR2c expression and signaling.

\section{Methods}

\section{Cells and treatments}

The human keratinocyte cell line $\mathrm{HaCaT}$, stably expressing FGFR2c (pBp-FGFR2c), overexpressing FGFR2b (pBp-FGFR2b) or the empty vector (pBp) were cultured in Dulbecco's modified eagle's medium (DMEM), supplemented with $10 \%$ fetal bovine serum (FBS) plus antibiotics.

For RNA interference and PKCe or ESRP1 silencing, cells were transfected with $\mathrm{PKC} \varepsilon$ small interfering RNA (PKC $\varepsilon$ siRNA) (Santa Cruz Biotechnology, Inc., Santa Cruz, CA, USA; sc36251), ESRP1 siRNA (Santa Cruz Biotechnology, SC77526), or an unrelated siRNA as a control, using Lipofectamine 2000 transfection reagent (Life Technologies, Carlsbad, CA, USA; 11,668-019) according to the manufacturer's protocol.

For growth factors stimulation, cells were left untreated or incubated with FGF7 (Upstate Biotechnology, Lake Placid, NY, 01-118) or with FGF2 (PeproTech, London, BFGF $100-188) 25 \mathrm{ng} / \mathrm{mL}$ for $24 \mathrm{~h}$ at $37^{\circ} \mathrm{C}$. To induce activation and signaling of FGFR2 isoforms, cells were serum starved and incubated with FGF7 or FGF2 $100 \mathrm{ng} / \mathrm{mL}$ for $10 \mathrm{~min}$ at $37^{\circ} \mathrm{C}$. For inhibition of FGFR2b and FGFR2c tyrosine kinase activity, cells were preincubated with a specific FGFR tyrosine kinase inhibitor, SU5402 $25 \mu \mathrm{M}$ (Calbiochem, Nottingham, UK; 572,630) for $1 \mathrm{~h}$ before treatments with growth factors (GFs).

\section{Invasion assay}

Migration assay was performed using 24-well transwell migration Boyden chambers $(8 \mu \mathrm{m}$ pore size; Costar, Cambridge, MA, USA) precoated with matrigel (dilution 1:2 in DMEM; BD Biosciences, Bedford, MA, USA). 5X $10^{4}$ cells were seeded in each filter and serum starved for $4 \mathrm{~h}$ at $37^{\circ} \mathrm{C}$. To induce chemotaxis: FGF2 $25 \mathrm{ng} / \mathrm{ml}$ was added to the lower chamber. After $48 \mathrm{~h}$, cells on the upper side of membranes were removed, while cells migrated on the bottom side were fixed in methanol and stained with toluidine blue. Quantitative analysis was assessed counting for each sample the migrated cells in 10 microscopic fields (objective used: 20X) from three independent experiments. Results have been expressed as mean values \pm SD. $p$ values were calculated using Student's $\mathrm{t}$ test and significance level has been defined as $p>0.05$.

\section{Western blot analysis}

Cells were lysed in a buffer containing $50 \mathrm{mM}$ HEPES, $\mathrm{pH} 7.5,150 \mathrm{mM} \mathrm{NaCl}, 1 \%$ glycerol, $1 \%$ Triton X-100, $1.5 \mathrm{mM} \mathrm{MgCl} 2,5 \mathrm{mM}$ EGTA, supplemented with protease inhibitors $(10 \mathrm{~g} / \mathrm{mL}$ aprotinin, $1 \mathrm{mM}$ phenylmethylsulfonyl fluoride [PMSF], $10 \mu \mathrm{g} / \mathrm{mL}$ leupeptin) and phosphatase inhibitors ( $1 \mathrm{mM}$ sodium orthovanadate, 20 $\mathrm{mM}$ sodium pyrophosphate, $0.5 \mathrm{M} \mathrm{NaF}$ ). A range of 20 to $50 \mu \mathrm{g}$ of total protein was resolved under reducing conditions by 8 or $12 \%$ SDS-PAGE and transferred to reinforced nitrocellulose (BA-S 83; Schleicher \& Schuell, Keene, NH, USA; BA-S83). The membranes were blocked with $5 \%$ nonfat dry milk (Bio-Rad Laboratories, Hercules, CA, USA, 170-6404) in PBS 0.1\% Tween 20 (Bio-Rad, 170-6531) and incubated with anti-p-PKC (Ser 645, Abcam, Cambridge, UK, ab108972), anti-Ecadherin (NCH-38, Dako, Carpinteria, CA, USA), anti$\beta 4$-integrin (7, Santa Cruz Biotechnology, sc-135,950), anti N-cadherin (Sigma-Aldrich, Saint Louis, MO, USA, C3865), monoclonal antibodies or with anti Bek (C17, Santa Cruz Biotechnology), p-PKCe (Ser729, Abcam, Cambridge, UK, ab63387), anti ESRP1 (Sigma-Aldrich, HPA023719), polyclonal antibodies, followed by enhanced chemiluminescence (ECL) detection (Thermo Scientific, Rockford, IL, USA; 34,580). The membranes were rehydrated by washing in PBS/Tween-20, stripped with $100 \mathrm{mM}$ mercaptoethanol and 2\% SDS for $30 \mathrm{~min}$ at $55^{\circ} \mathrm{C}$ and probed again with, anti-PKCe (Abcam, ab124806), anti-PKC $\delta$ (Santa Cruz Biotechnology) polyclonal antibodies, or with anti-actin (Sigma-Aldrich, A5441) monoclonal antibody to estimate the protein equal loading. Densitometric analysis was performed using Quantity One Program (Bio-Rad). The resulting values from three different experiments were normalized and expressed as fold increase respect to the control value. Values from a representative of three independent 


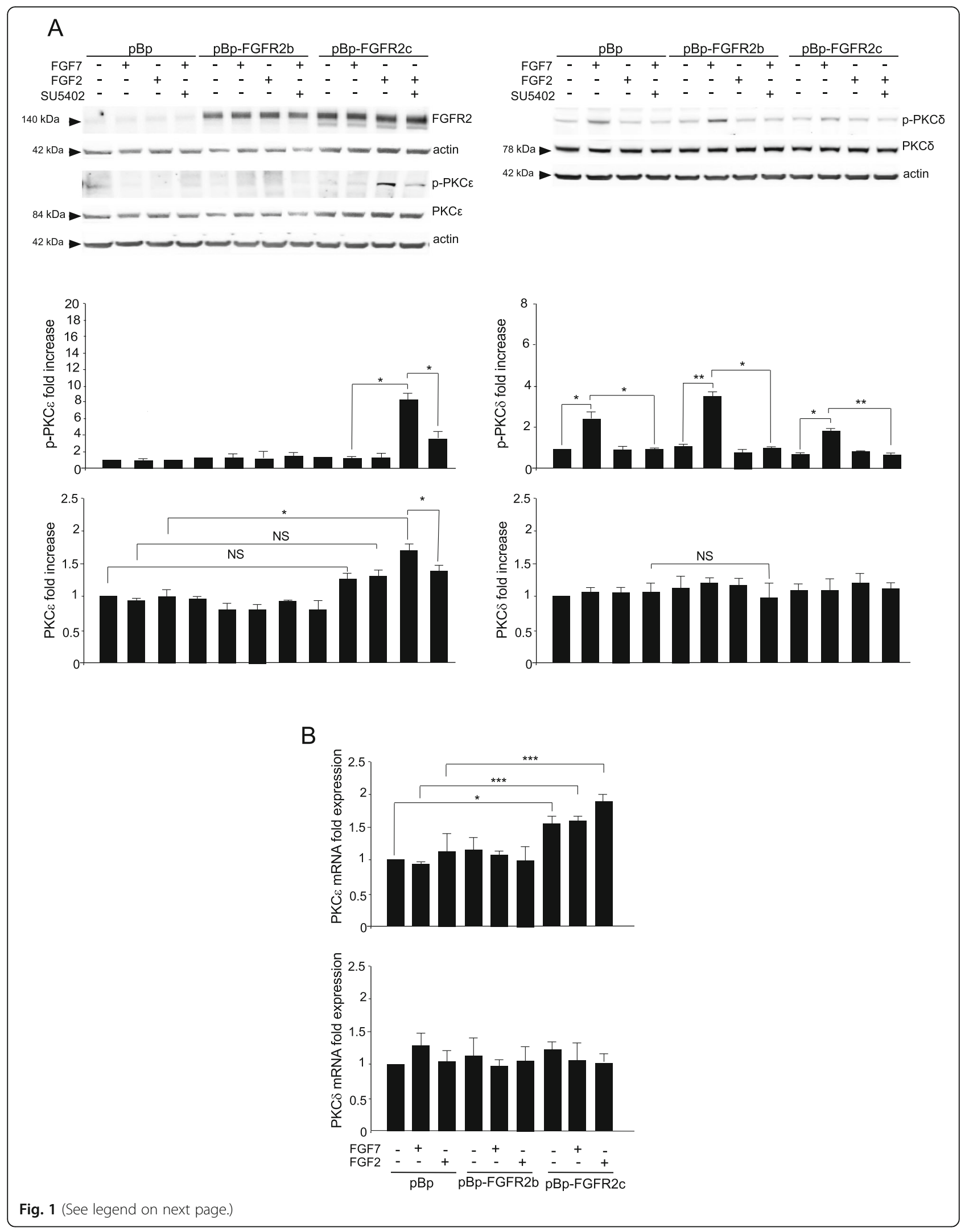


(See figure on previous page.)

Fig. 1 FGFR2C aberrant expression and signaling induce PKC $\varepsilon$ activation. HaCaT clones stably transduced with pBp-FGFR2c or with pBp-FGFR2b or empty pBp vector, used as controls, were left untreated or stimulated with FGF7 or with FGF2 in presence or absence of the FGFR tyrosine kinase inhibitor SU5402 as described in Material and Methods. a Western blot analysis shows that the $140 \mathrm{KDa}$ band corresponding to the molecular weight of FGFR2 is mainly evident in cells transduced with FGFR2b or FGFR2c isoforms. An appreciable phosphorylation of PKC $\varepsilon$ at the autophosphorylation site Ser 729 is observed only in pBp-FGFR2c clones upon FGF2 stimulation and this effect is abolished by SU5402. A moderate up-regulation of PKC $\varepsilon$ protein level is detectable only in pBp-FGFR2c clones, particularly in response to FGF2. A moderate phosphorylation of PKC $\delta$ at the autophosphorylation site Serine 645, is visible in all clones in response to FGF7 stimulation, while no evident modulation of PKC $\delta$ protein level is observed. Equal loading was assessed for p-PKC $\varepsilon$ with the anti-PKC $\varepsilon$ antibody, for p-PKC $\delta$ with the anti-PKC $\delta$ antibody, for PKC $\varepsilon$ and PKC $\delta$ with the anti-actin antibody. For the densitometric analysis, the values from 3 independent experiments were normalized, expressed as fold increase and reported in graph as mean values \pm standard deviation (SD). Student $t$ test was performed and significance levels have been defined as $p<0.05:{ }^{*} p<0.05,{ }^{* *} p<0.01$. b Real time RT-PCR analysis shows a positive modulation of PKC $\varepsilon$ expression at mRNA transcript level only in pBp-FGFR2C clones, particularly in response to FGF2. No evident modulation of PKC $\delta$ mRNA expression is observed. Results are expressed as mean value \pm standard error (SE). Student's $t$ test was performed and significance levels were defined as $p<0.05:{ }^{*} p<0.05,{ }^{* * *} p<0.001$

experiments were reported in each figure. The student's $t$ test was performed and significance levels have been defined as $p<0.05$.

\section{Primers}

Oligonucleotide primers were purchased from Invitrogen (Carlsbad, CA, USA). The following primers were used: for the PKCe target gene: 5' - GGTGAAGCCCC TAAAGACAATG-3' (sense), 5'-GACCTGATGGACCC TGCG-3' (antisense); for the PKC $\delta$ target gene: 5'CGCATCGCCTTCAACTCCTA-3' (sense), 5'-AGTGT TTTCCCACGCTCTGT-3' (antisense); for the Ecadherin target gene: $5^{\prime}$-TGGAGGAATTCTTGCTTT GC-3' (sense), 5' -CGCTCTCCTCCGAAGAAAC-3' (antisense); for the $\beta 4$-integrin target gene: $5^{\prime}$-GGGAAA AAGCAAGACCACACC-3' (sense), 5'-CCCTCTGTTC CACCTGCTTC-3' (antisense); for the vimentin target gene: 5' -AAATGGCTCGTCACCTTCGT-3' (sense), 5' AGAAATCCTGCTCTCCTCGC-3' (antisense); for the Snail1 target gene: 5'-GCTGCAGGACTCTAATCCAGA-3' (sense), 5'-ATCTCCGGAGGTGGGATG-3' (antisense); for the STAT3 target gene: 5'-CAGAGA TGTGGGAATGGGGG-3' (sense), 5' - TGGCAAGGAG TGGGTCTCTA-3' (antisense); for the FRA1 target gene: 5' - GCAGGCGGAGACTGACAAA-3' (sense), 5' GATGGGTCGGTGGGCTTC-3', for ESRP1 target gene: 5'-GGCTCGGATGAGAAGGAGTT-3' (sense), 5'-GCACTTCGTGCAACTGTCC-3' (antisense); for FGFR2b target gene: 5'-CGTGGAAAAGAACGGCAG TAAATA-3' (sense), 5'-GAACTATTTATCCCCGAG TGCTTG-3' (antisense); for FGFR2c target gene: 5' TGAGGACGCTGGGGAATATACG-3' (sense), 5' -TA GTCTGGGGAAGCTGTAATCTCCT 3' (antisense); for the 18S rRNA housekeeping gene: 5'-CGAGCCGCCT GGATACC-3' (sense) and 5'-CATGGCCTCAGTTC CGAAAA-3' (antisense). For each primer pair, we performed no-template control and no-reverse- transcriptase control (reverse transcription [RT]-negative) assays, which produced negligible signals.

\section{RNA extraction and CDNA synthesis}

RNA was extracted using the TRIzol method (Invitrogen, 15,596,018) according to the manufacturer's instructions and eluted with $0.1 \%$ diethylpyrocarbonate (DEPC)-treated water. Each sample was treated with DNase I (Invitrogen, 18,068-015). The total RNA concentration was quantitated by spectrophotometry; $1 \mu \mathrm{g}$ of total RNA was used for reverse transcription using the iScriptTM cDNA synthesis kit (Bio-Rad, 170-8891) according to the manufacturer's instructions.

\section{PCR amplification and real-time quantitation}

Real-time RT-PCR was performed using the iCycler real-time detection system (iQ5 Bio-Rad) with optimized PCR conditions. The reactions were carried out in a 96well plate using iQ SYBR green supermix (Bio-Rad, 1, 708,882 ), adding forward and reverse primers for each gene and $1 \mu \mathrm{l}$ of diluted template cDNA to a final reaction mixture volume of $15 \mu \mathrm{l}$. All assays included a negative control and were replicated three times. Real-time quantitation was performed with the help of the iCycler IQ optical system software, version 3.0a (Bio-Rad), according to the manufacturer's manual. Results are reported as mean values \pm SE from three different experiments in triplicate. The student's $t$ test was performed, with significance levels defined as $P$ values < 0.05 .

\section{Results}

PKC $\varepsilon$ signaling is responsible for FGFR2c-mediated modulation of EMT-related markers

In order to verify whether PKC $\varepsilon$ could be responsible for the multiple oncogenic outcomes of aberrant FGFR2c expression, we first assayed the ability of this receptor to 

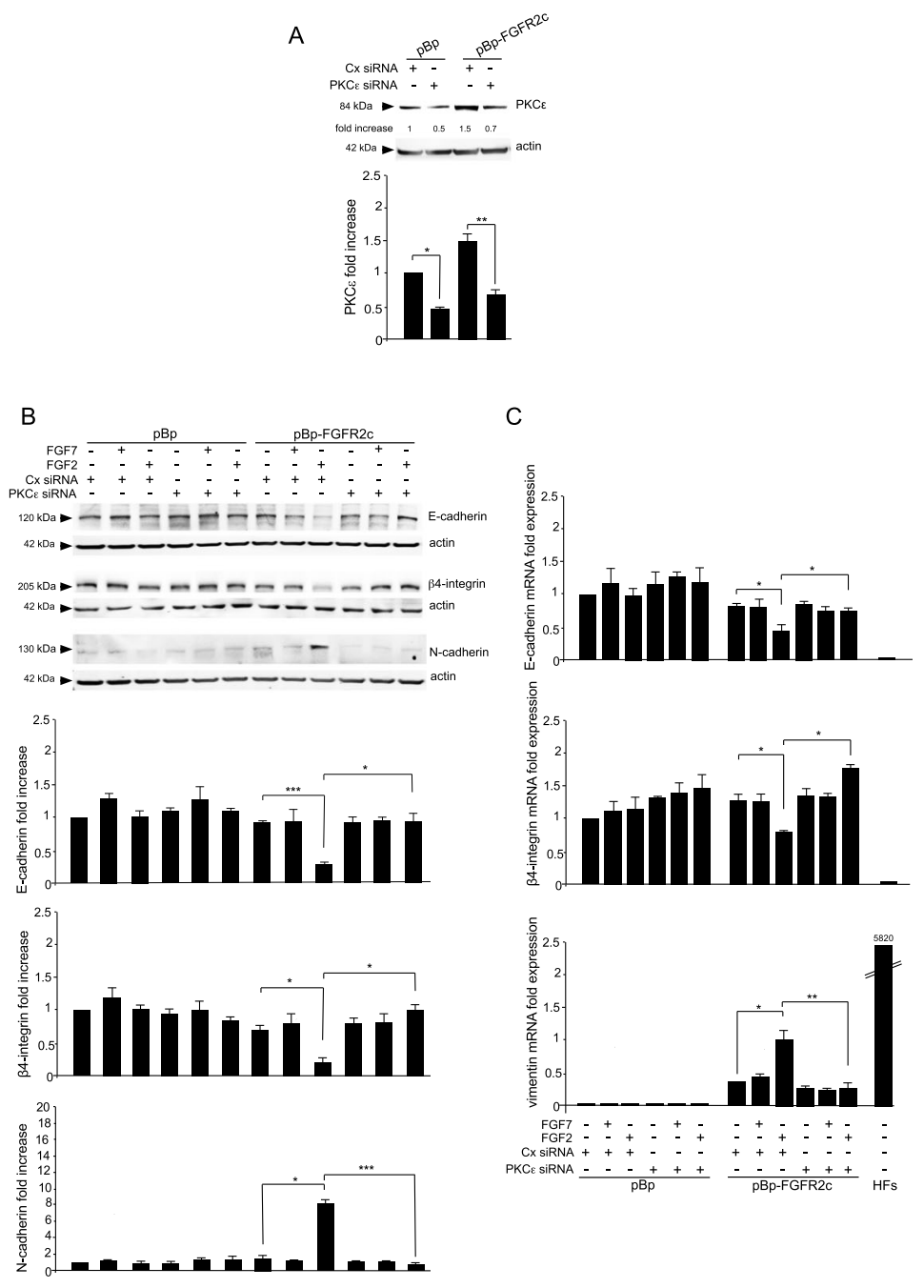

D
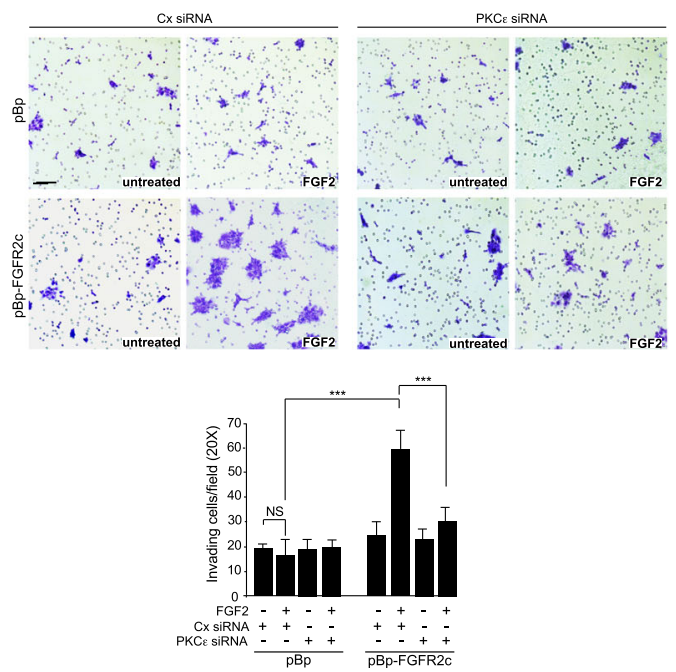

Fig. 2 (See legend on next page.) 


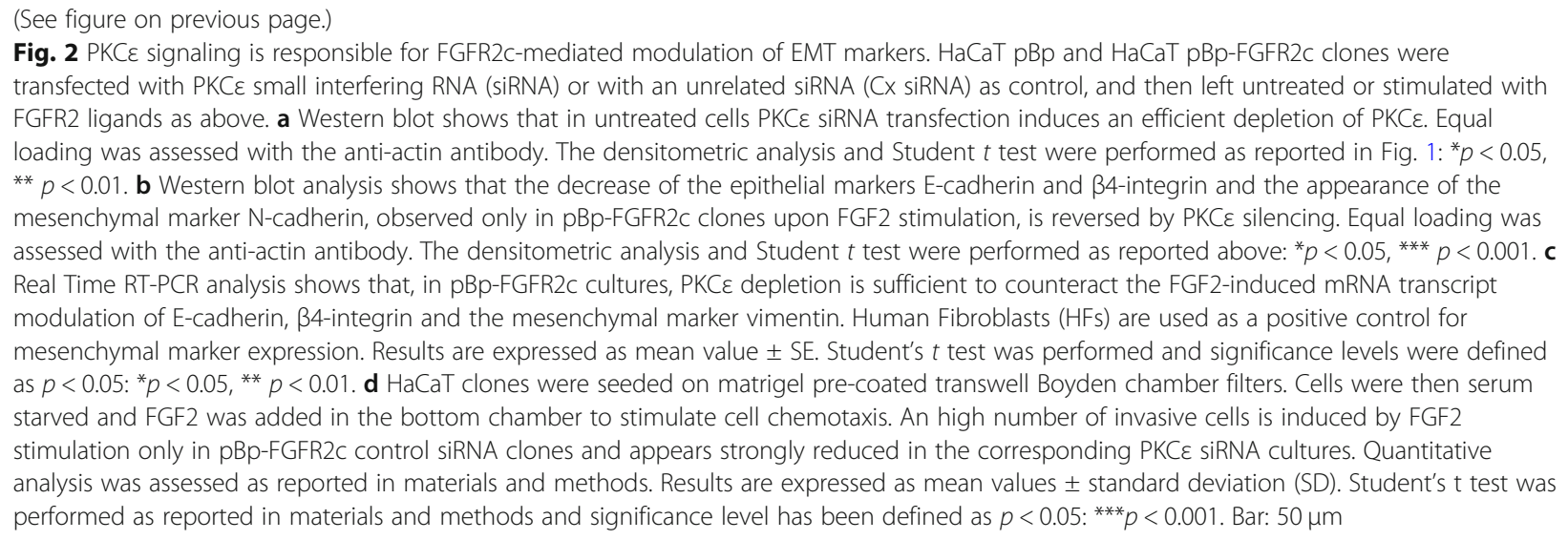

impact on $\mathrm{PKC} \varepsilon$ activity. To this aim, we took advantage of the human keratinocyte $\mathrm{HaCaT}$ clones stably transduced with pBp-FGFR2c retroviral constructs or with pBp-FGFR2b or empty pBp vector, used as controls [10]. Cells were left untreated or stimulated with FGF7, the specific ligand of FGFR2b, or with FGF2, which does not bind to FGFR2b, but is able to activate other FGFRs including FGFR2c. To assess the involvement of PKCe, we verified its phosphorylation in Ser 729 in the C-terminal hydrophobic motif, which depends on the internal catalytic activity of the kinase and is a widely recognized indicator of $\mathrm{PKC \varepsilon}$ activation $[17,18]$. Western blot analysis showed that an appreciable phosphorylation of PKC $\varepsilon$ at the autophosphorylation site Ser 729 was visible only in $\mathrm{HaCaT}$ pBp-FGFR2c clones upon FGF2 stimulation (Fig. 1a) and this effect was abolished by the presence of the specific FGFR tyrosine kinase inhibitor SU5402 (Fig. 1a). Thus, PKCE activation could be, in our cell model, specifically ascribed to the FGFR2c expression and signaling. In addition, the moderate increase of $\mathrm{PKC} \varepsilon$ at both protein (Fig. 1a) and mRNA transcript levels (Fig. 1b), detectable only in pBp-FGFR2c clones, particularly in response to FGF2, suggested that FGFR2c activation also induced an appreciable up-regulation of this protein. The phosphorylation of $\mathrm{PKC} \delta$ at the autophosphorylation site Serine 645, which belongs to the characteristic phosphorylation pattern of PKC $\delta$ activation [19] was observed in all clones only in response to FGF7 (Fig. 1a), was in agreement with our recent data proposing a key role of this PKC family member in the early steps of FGF7-mediated keratinocyte differentiation [7]. No evident modulation of both PKC $\delta$ protein (Fig. 1a) and mRNA (Fig. 1b) was detected in all clones, as expected [7].

To assess the PKCe contribution in FGFR2c-mediated modulation of EMT marker expression, we performed its depletion via small-interfering RNA approaches. $\mathrm{HaCaT}$ pBp-FGFR2c and $\mathrm{HaCaT}$ pBp clones were transfected with $\mathrm{PKC} \varepsilon$ siRNA or with an unrelated siRNA as control (Cx siRNA) and the efficiency of protein depletion was first verified by Western blot analysis (Fig. 2a). Transfected cells were left untreated or stimulated with FGFR2 ligands as above. Western blot analysis showed that both the decrease of the epithelial markers Ecadherin and $\beta 4$-integrin and the appearance of the mesenchymal marker N-cadherin, evident only in $\mathrm{pBp}$ FGFR2c clones by FGF2 stimulation, were reversed by $\mathrm{PKC} \varepsilon$ silencing (Fig. 2b). These findings were also validated by Real Time RT-PCR analysis, showing that, in pBp-FGFR2c cultures, PKCe depletion was sufficient to counteract the FGF2-induced mRNA transcript modulation of E-cadherin, $\beta 4$-integrin and the mesenchymal marker vimentin (Fig. 2c).

Based on our previous findings on the role of FGFR2c in conferring invasiveness in the well-established noninvasive $\mathrm{HaCaT}$ cells $[8,10]$ we assessed the impact of $\mathrm{PKC} \varepsilon$ depletion on this acquired ability. To this aim we analyzed the capacity of $\mathrm{HaCaT}$ pBp-FGFR2c and $\mathrm{HaCaT}$ pBp cells to migrate through transwell Boyden chambers pre-coated with a thin layer of matrigel, a gel composed of reconstituted basement membrane elements resembling the basement membrane in vivo. Upon seeding, cells were left untreated or stimulated with FGF2 for $48 \mathrm{~h}$. Since the stimulation with FGF7 did not appear to impact on EMT-related marker expression in both pBp and FGFR2c clones (Fig. 2b, c), this treatment was not performed. The results showed that the significant increase of invading cells, observed only in FGFR2c cultures in response to FGF2 (Fig. 2d), was clearly impaired by $\mathrm{PKC} \varepsilon$ silencing (Fig. 2d). Thus, the expression and possibly activation of $\mathrm{PKC} \varepsilon$ appears to significantly contribute to the appearance of early tumorigenic features.

\section{PKC $\varepsilon$ signaling acts via the induction of the EMT-related transcription factors}

We have previously demonstrated that the aberrant signaling of FGFR2c in the epithelial context induces 
A

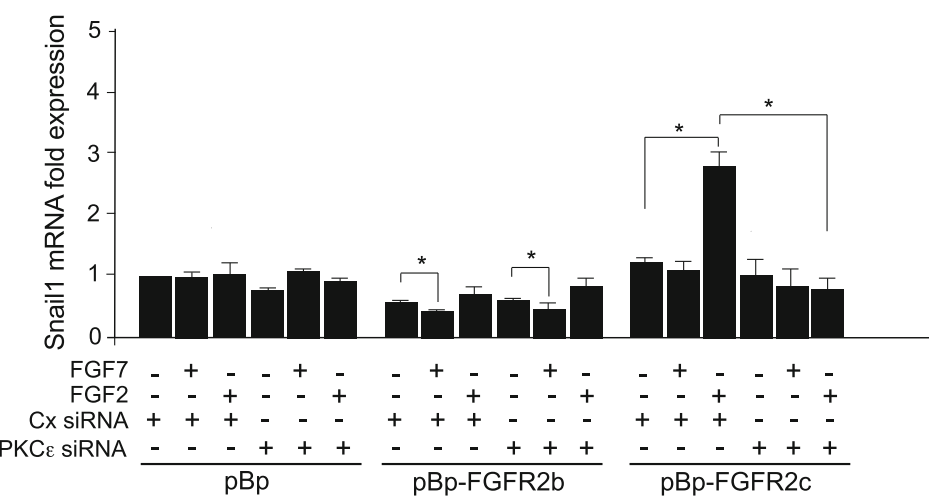

B

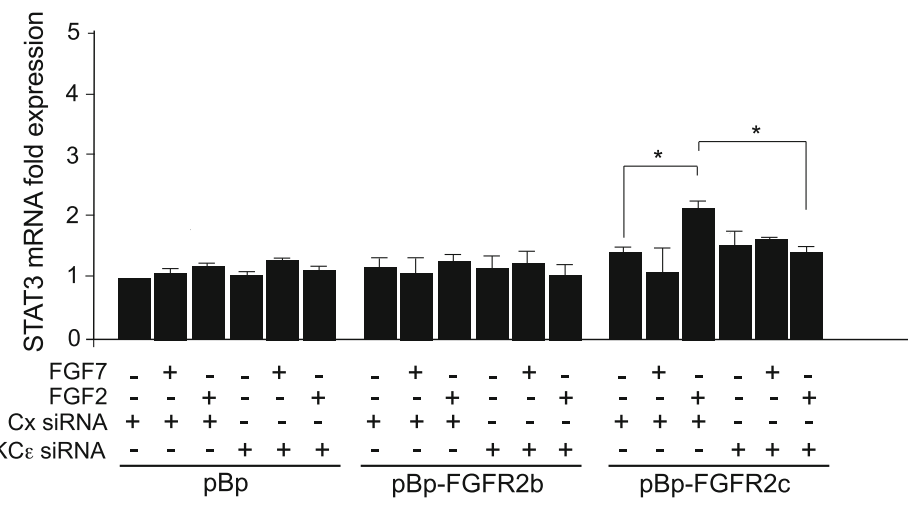

C

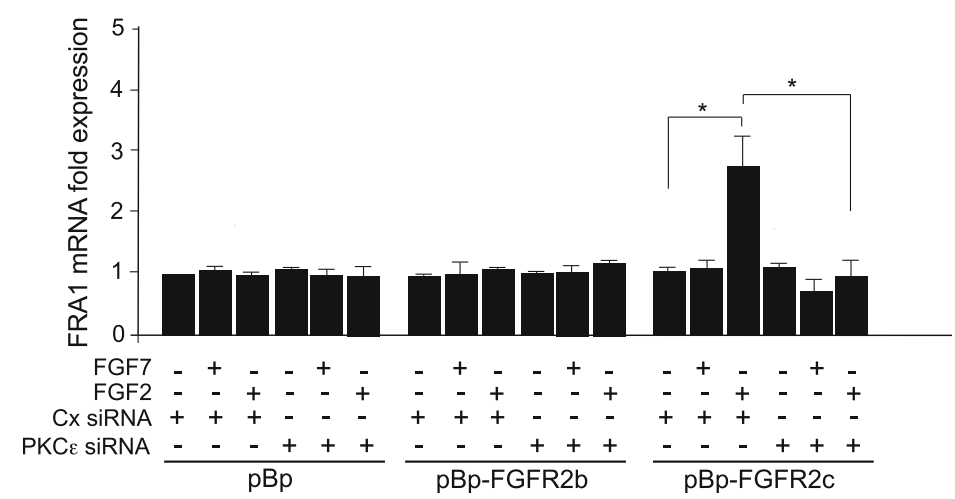

Fig. 3 (See legend on next page.) 
(See figure on previous page.)

Fig. 3 PKC $\varepsilon$ signaling is responsible for FGFR2c-mediated induction of the EMT-related transcription factors. Clones were transfected with PKC $\varepsilon$ siRNA or with CX siRNA and left untreated or stimulated with FGFR2 ligands as above. a Real-time RT-PCR shows that the increase of the master transcription factor for EMT Snail1, evident only in pBp-FGFR2c clones following FGF2 stimulation, is abolished by PKC $\varepsilon$ silencing. On the contrary, in pBp-FGFR2b clones Snail1 transcript expression is slightly repressed, particularly in response to FGF7, while PKC $\varepsilon$ silencing does not affect this trend. $\mathbf{b}$ A significant induction of STAT3 mRNA transcript level is observed in pBp-FGFR2c clones stimulated with FGF2 and this effect is abolished by PKCE silencing. No modulations of RNA transcripts are observed in control clones in response to FGF7. c Real-time RT-PCR shows that FRA1 mRNA transcript levels are significantly induced by FGF2 stimulation only in FGFR2c-expressing culture. This effect appears significantly inhibited by PKC $\varepsilon$ depletion. No effects are observed in control clones in response to FGF7. Results are expressed as mean value \pm SE. Student's $t$ test was performed and significance levels were defined as $p<0.05 .{ }^{*} p<0.05$

expression of Snail1 [10], which is the master transcription factor for EMT $[20,21]$ and mainly associated with the EMT onset [22]. Therefore, to assess whether the depletion of PKCE protein could be able to block the initiation of FGFR2c-induced EMT, expression of Snail1 mRNA was investigated in all $\mathrm{HaCaT}$ clones transfected with PKCe siRNA or with control siRNA and stimulated with FGFR2 ligands as above. Real-time RT-PCR showed that the increase of Snail1 mRNA expression, evident only in pBp-FGFR2c clones following FGF2 stimulation, was abolished by $\mathrm{PKC} \varepsilon$ silencing (Fig. 3a). As expected [10] and in agreement with its proposed role as tumor suppressor, the overexpression of FGFR2b isoform slightly repressed Snail1 transcript expression, particularly in response to its ligand FGF7 (Fig. 3a), while PKC $\varepsilon$ silencing did not affect this trend (Fig. 3a). Thus, the selective shut-off of $\mathrm{PKC \varepsilon}$ signaling is ineffective on FGFR2b-dependent modulation of Snail1, but it appears to be sufficient to inhibit its FGFR2c-mediated induction.

It has been previously described that, during EMT, Snail1 can be induced by the transcription factor STAT3. Interestingly, STAT3, which is up-regulated in several human carcinomas, including head and neck squamous cell carcinoma (HNSCC), breast, ovary, prostate, and lung cancer [23-27], is specifically activated by PKCe $[12,28]$. Since STAT3 is also induced and activated by several FGFRs, including FGFR2 [29], we wondered whether, in the context of human keratinocytes aberrantly expressing FGFR2c, this transcription factor could act downstream $\mathrm{PKC} \varepsilon$ and possibly upstream Snail1. Real time RT-PCR showed a significant induction of STAT3 in pBp-FGFR2c clones stimulated by FGF2 (Fig. 3b), which was abolished by PKCe silencing (Fig. $3 \mathrm{~b}$ ), while no modulations of RNA transcripts were detected in control clones in response to FGF7, even when FGFR2b was overexpressed (Fig. 3b). Thus, STAT3 appears to be an effector exclusive for the FGFR2c isoform, whose activation take place downstream PKCe.

Because EMT is also triggered by Snail-dependent induction of FRA1 [30], another transcription factor activated by FGFRs, including FGFR2 [31], we wondered if FRA1 would be also induced by PKCe during FGFR2c- driven EMT. Real-time RT-PCR showed that, similarly to what observed for Snail1 and STAT3, FRA1 mRNA transcripts were significantly induced by FGF2 stimulation only in FGFR2c-expressing culture (Fig. 3c) and this effect appeared significantly inhibited by $\mathrm{PKC} \varepsilon$ depletion (Fig. 3c). No modulating effects were observed in control clones in response to FGF7 suggesting that, similarly to STAT3 and Snail1, also FRA1 is an exclusive effector of FGFR2c (Fig. 3c).

\section{The activation of PKC $\varepsilon$ is the key molecular event triggered by FGFR2 isoform switch and underlying EMT induction}

In order to assess if the switching from the epithelial FGFR2b versus the mesenchymal FGFR2c isoform could represent the specific event responsible for PKC $\varepsilon$ activation and consequent EMT induction in human keratinocytes, we performed the depletion of the epithelial splicing regulatory protein1 (ESRP1) which is responsible for the FGFR2 splicing and consequent expression of FGFR2b in epithelial context $[9,32]$. HaCaT cells were transfected with ESRP1 siRNA or with an unrelated siRNA (Cx siRNA), as control, and then stimulated with FGF7 or FGF2, as reported above. The efficiency of ESRP1 depletion was verified by biochemical approaches (Fig. 4a). Then, real time RT-PCR was performed to assess the decrease of FGFR2b expression (Fig. 4b, left panel) and the appearance of FGFR2c (Fig. 4b, right panel) following ESRP1 depletion, confirming that the correct splicing of the FGFR2 gene, occurring in epithelial context, has been impaired. Then, focusing our attention on $\mathrm{PKC} \varepsilon$ signaling, Western blot analysis showed that ESRP1 depletion and consequent FGFR2 isoform switch was sufficient to make $\mathrm{HaCaT}$ cells responsive to FGF2 in term of $\mathrm{PKC} \varepsilon$ activation/phosphorylation (Fig. 4c). This event was accompanied by EMT induction, as demonstrated by E-cadherin repression and $\mathrm{N}$-cadherin appearance (Fig. $4 \mathrm{~d}$ ), as well as by the up-regulation of the three EMT-related transcription factors STAT3, Snail1 and FRA1 (Fig. 4e). The effects observed after ESRP1 depletion were comparable to those observed in $\mathrm{HaCaT}$ clones expressing FGFR2c (see Figs. 1, 2 and 3). Interestingly, all the above effects 
A

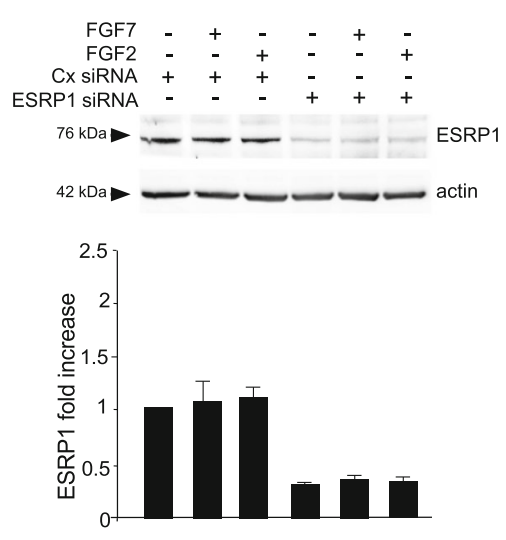

C

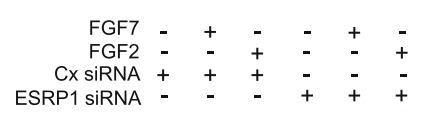
ESRP1 SiRNA
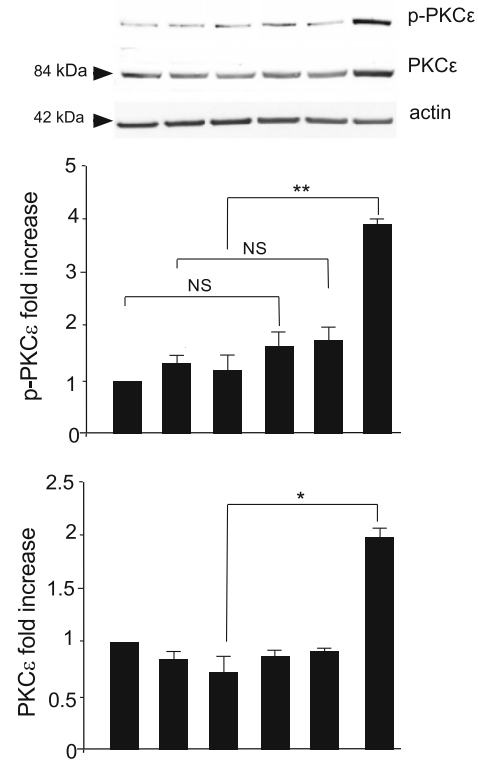

B

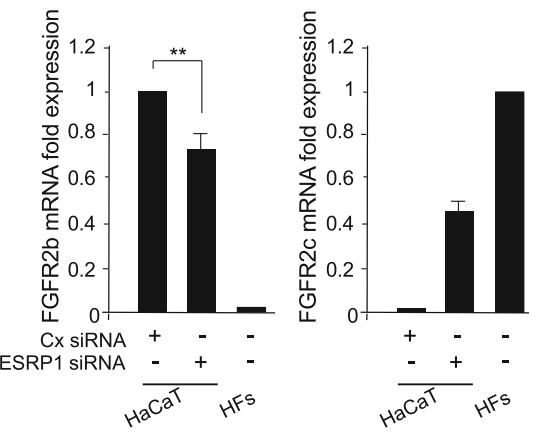

D
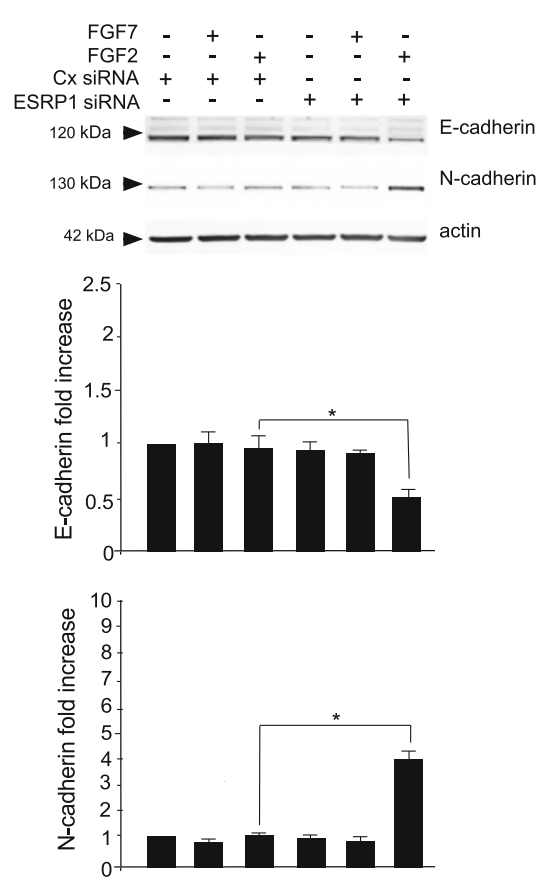

E
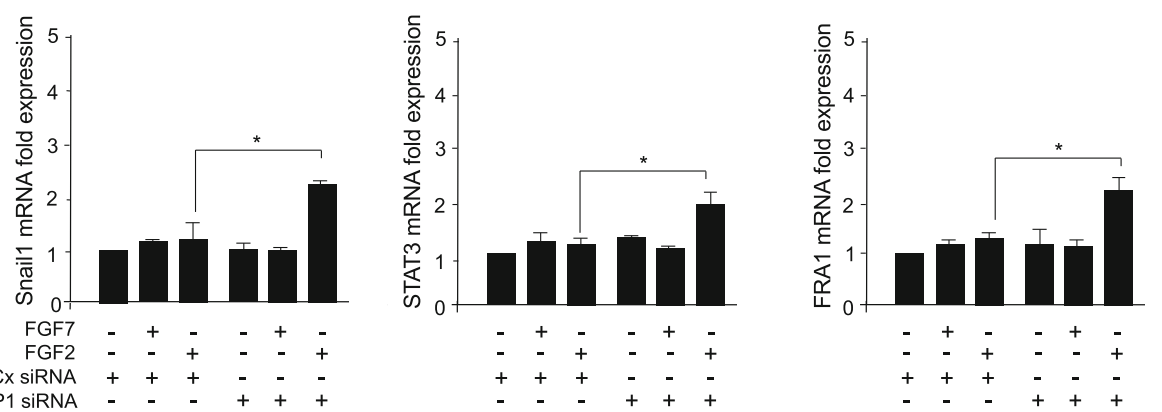

Fig. 4 (See legend on next page.) 
(See figure on previous page.)

Fig. 4 FGFR2 isoform switch triggers PKC $\varepsilon$ activation, as well as induction of EMT. HaCaT cells were transfected with siRNA for ESRP1 or with an unrelated siRNA (CX siRNA), as control, and then left untreated or stimulated with FGF7 or FGF2, as above. a Western blot analysis shows that ESRP1 siRNA induces an efficient depletion of ESRP1. Equal loading was assessed with the anti-actin antibody. The densitometric analysis was performed as reported above. $\mathbf{b}$ Real-time RT-PCR shows that ESRP1 silencing leads to the decrease of FGFR2b expression and to the appearance of FGFR2c mRNA transcript levels. HFs are used as a positive control for FGFR2c expression. Results are expressed as mean value \pm SE. Student's $t$ test was performed and significance levels were defined as $p<0.05$. ${ }^{*} p<0.01$. $\mathbf{c}$, d Biochemical approaches show that ESRP1 depletion is sufficient to make HaCaT cells responsive to FGF2 in terms of PKC $\varepsilon$ activation/phosphorylation and EMT induction, as demonstrated by E-cadherin repression and $\mathrm{N}$-cadherin appearance. Equal loading was assessed with the anti-actin antibody. The densitometric analysis and Student $t$ test were performed as reported above: ${ }^{*} p<0.05,{ }^{* *} p<0.01$. e Real-time RT-PCR shows that ESRP1 depletion, upon FGF2 stimulation, induces the upregulation of the three EMT-related transcription factors Snail1, STAT3 and FRA1. Results are expressed as mean value \pm SE. Student's $t$ test was performed and significance levels were defined as $p<0.05 .{ }^{*} p<0.05$

triggered by FGF2 after ESRP1 depletion were significantly counteracted by both the co-depletion of PKCE and/or the treatment with the FGFR2 inhibitor SU5402 (Fig. 5b-d), confirming that FGFR2c activation and PKC $\varepsilon$ signaling take place downstream FGFR2 isoform switch and are required for EMT induction. In contrast, neither PKCe silencing or SU5402 treatment appear to be able to interfere with FGFR2 isoform switch induced by ESRP1 depletion (Fig. 5a).

\section{Discussion}

To clarify how the diversification of the complex network of receptor tyrosine kinase (RTK) signaling is regulated is presently considered a crucial topic, since the impairment of this regulation is increasingly described in several diseases, including cancer. In particular for FGFRs, the isoform switching is one of the proposed ways for signaling deregulation involved in both epithelial-mesenchymal transition (EMT) and cancer progression [2-4]. In this regard, previous works from our group have demonstrated that FGFR2 isoform switch and the consequent aberrant expression of the mesenchymal FGFR2c isoform in human keratinocytes is responsible for impairment of differentiation [8], EMT induction and appearance of early tumorigenic features $[9,10]$. However, clear knowledge of the molecular players of the oncogenic signaling established by the aberrant expression of the mesenchymal FGFR2c isoform in the epithelial context is still lacking.

The findings reported in the present work appears to indicate that PKC $\varepsilon$ activation could be a key molecular signaling event occurring as a consequence of FGFR2c expression. In particular, the experiments of depletion of ESRP1, involved in FGFR2 splicing in epithelial cells, indicated that the activation of PKCE is the key molecular event triggered by FGFR2 isoform switch and underlying EMT induction in human keratinocytes. Our findings are consistent with several evidences indicating that expression of FGFR2c correlates with EMT induction and with the acquisition of a more aggressive, invasive phenotype in different epithelial tumor cell lines [33]. Interestingly, in some of these cell lines, such as prostate cancer cells, a crucial role has been also in parallel proposed for PKCe in the induction of EMT and cell invasion [15].

In this scenario, PKCe would act upstream an oncogenic signaling network, leading to the induction of EMT-related transcription factors such as STAT3, Snail1 and FRA1, which are probably induced in cascade and cooperate with each other in triggering and sustaining the EMT program.

Interestingly, the different specificity in PKC isoform activation displayed by FGFR2b and FGFR2c in our cellular model is consistent with the recent advanced hypothesis that the alternative splicing could represent the emerging mechanism to diversify FGFR signaling [34]. In fact, splicing events might alter the FGFR2 interactions with a huge number of other membrane proteins, such as other RTKs or G-protein-coupled receptors (GPCRs), impacting on the downstream scaffold protein formation and consequently on the signaling transduced by these multiprotein complexes at the plasma membrane [33]. In light of these assumptions, it is reasonable suppose that the formation of these complexes could affect also the relocalization of FGFRs and of their signaling substrates to specific subcellular environments, containing the appropriate downstream targets: this could be essential to determine the output of a specific signaling cascade [34].

Among the different RTK signaling players, PKCs are a class of finely regulated serine-threonine kinases that are essential for the control of higher-level signal organization as well as spatial distribution of the signals [13, 35]. In fact, it has been proposed that PKCs can be recruited to membrane protein scaffolds, where they may control the behavior of protein complexes influencing their assembly state, but also their subcellular localization and their ability to recruit different downstream effectors [35]. This is particularly true for PKCe for which many cell-type- and context-specific signaling functions have been demonstrated to regulate several 
A
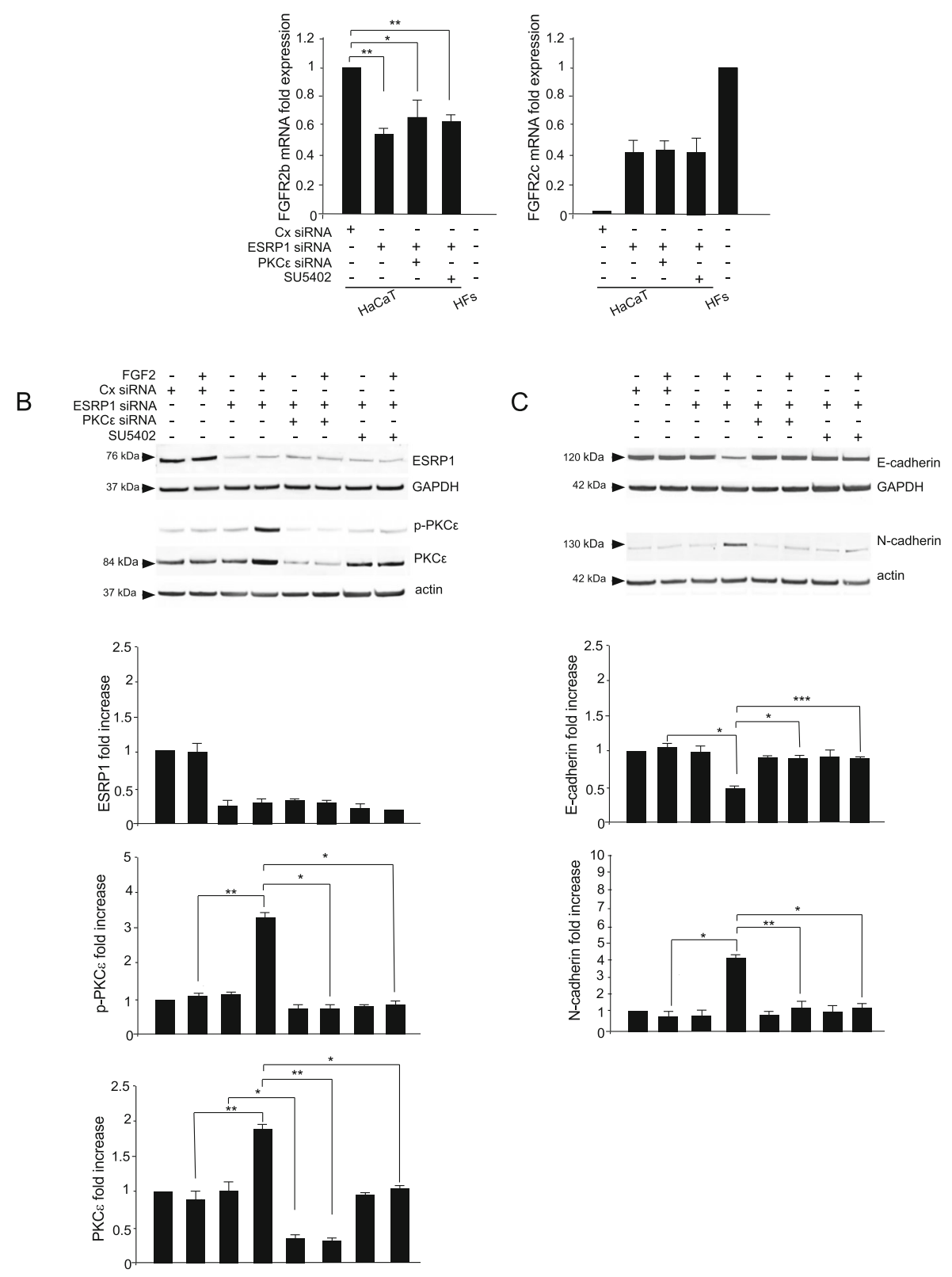

D

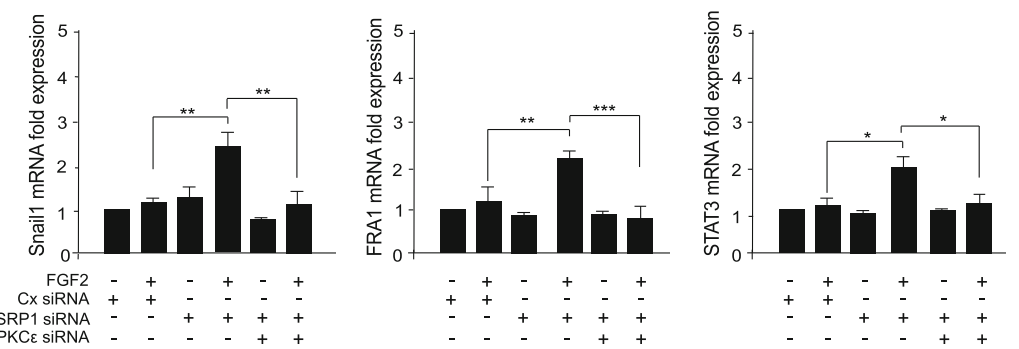

Fig. 5 (See legend on next page.) 
(See figure on previous page.)

Fig. 5 PKC $\varepsilon$ depletion, as well as the inhibition of FGFR2C kinase activity counteract FGFR2 isoform switch-induced EMT. HaCaT cells were transfected with siRNA for ESRP1 or co-trasfected with with siRNA for ESRP1 and siRNA for PKCE. The transfection with unrelated siRNA (CX siRNA) was used as control. Cells were then left untreated or stimulated with FGF2 in presence or absence of SU5402 as above. The densitometric analysis was performed as reported above. a Real-time RT-PCR shows that the decrease of FGFR2b expression and to the appearance of FGFR2c mRNA transcripts induced ESRP1 silencing is not affected by PKC $\varepsilon$ depletion or by the presence of SU5402. Results are expressed as mean value \pm SE. Student's $t$ test was performed and significance levels were defined as $p<0.05 .{ }^{*} p<0.05,{ }^{* *} p<0.01$. b, c Biochemical approaches show that ESRP1 and PKC $\varepsilon$ siRNA induces an efficient depletion of ESRP1 and PKC $\varepsilon$ protein levels (b). PKC $\varepsilon$ activation/phosphorylation (b), as well as Ecadherin downregulation and N-cadherin appearance (c), induced by ESRP1 depletion, are efficiently inhibited by both the depletion of PKC $\varepsilon$ or the treatment with SU5402. The densitometric analysis and Student $t$ test were performed as reported above: ${ }^{*} p<0.05,{ }^{* *} p<0.01,{ }^{* * *} p<0.001$. d Real-time RT-PCR shows that the depletion of PKC $\varepsilon$ is sufficient to block the induction of the EMT-related transcription factors, evident in ESRP1-depleted cells in response to FGF2. Results are expressed as mean value \pm SE. Student's $t$ test was performed as above. ${ }^{*} p<0.05$, ${ }^{* *} p<$ $0.01,{ }^{* * *} p<0.001$

cellular processes not only via the phosphorylation of multiple and alternative downstream substrates, but also through their relocalization to different intracellular sites [36].

\section{Conclusions}

Taken all together our results, which point to the identification of downstream $\mathrm{PKC}$ isoforms exclusive for each of the FGFR2 isoforms, such as PKC $\delta$ for FGFR2b and $\mathrm{PKC} \varepsilon$ for FGFR2c, represent the first step to advance our understanding of the molecular bases of FGFR signaling deregulation occurring in epithelial tissues from the physiological oncosoppressive to the pathological oncogenic profile.

\section{Abbreviations \\ DAPI: 4',6-diamidino-2-phenylindole; EMT: Epithelial-mesenchymal transition; ESRP: Epithelial Splicing Regulatory Protein; FGF2: Fibroblast growth factor 2 (basic); FGF7/KGF: Fibroblast growth factor 7; FGFR: Fibroblast growth factor receptor; GPCRs: G-protein-coupled receptors; HaCaT: Human adult skin keratinocytes propagated under low calcium; HNSCC: Head and neck squamous cell carcinoma; HFs: Human fibroblasts; HKs: Human keratinocytes; PKC: Protein kinase C; RTK: Receptor tyrosine kinase; SCC: Squamous cell carcinomas; SD: Standard deviation; SDS-PAGE: Sodium dodecyl sulphate- polyacrylamide gel electrophoresis; SE: Standard error; siRNA: Small interfering RNA}

\section{Acknowledgements}

Not applicable.

\section{Authors' contributions}

M.R.T and F.B. have made substantial contribution to conception and design of the project, M.N., D.R., M.R.T and F.B. have been involved in drafting the manuscript and has given final approval of the version to be published. M.N., D.R. and F.P. have made substantial contributions to acquisition and analysis of the data and have given final approval of the version to be published. All authors read and approved the final manuscript.

\section{Funding}

This work was partially supported by grants from MIUR- Ministero dell'Istruzione dell'Università e della Ricerca and from AIRC - Associazione Italiana per la Ricerca sul Cancro, Italy (Grant number: IG 15858).

\section{Availability of data and materials}

The dataset used and/or analyzed during the current study are available from the corresponding author on reasonable request.
Ethics approval and consent to participate

Not applicable.

\section{Consent for publication}

All authors agree to the publication.

\section{Competing interests}

The authors declare that they have no competing interests.

\section{Author details}

${ }^{1}$ Department of Clinical and Molecular Medicine, Sapienza University of Rome, Laboratory Affiliated to Istituto Pasteur Italia - Fondazione Cenci Bolognetti, Viale Regina Elena 324, 00161 Rome, Italy. ${ }^{2}$ S. Andrea University Hospital, Rome, Italy.

Received: 20 January 2020 Accepted: 16 April 2020

Published online: 19 May 2020

References

1. Wang $\mathrm{BD}$, Lee $\mathrm{NH}$. Aberrant RNA splicing in cancer and drug resistance. Cancers. 2018;10:458

2. Oltean S, Sorg BS, Albrecht T, Bonano VI, Brazas RM, Dewhirst MW, et al. Alternative inclusion of fibroblast growth factor receptor 2 exon IIIc in dunning prostate tumors reveals unexpected epithelial mesenchymal plasticity. Proc Natl Acad Sci U S A. 2006;103:14116-21.

3. Shirakihara T, Horiguchi K, Miyazawa K, Ehata S, Shibata T, Morita I, et al. TGF- $\beta$ regulates isoform switching of FGF receptors and epithelialmesenchymal transition. EMBO J. 2011;30:783-95.

4. Zhao Q, Caballero OL, Davis ID, Jonasch E, Tamboli P, Yung WK, et al. Tumor-specific isoform switch of the fibroblast growth factor receptor 2 underlies the mesenchymal and malignant phenotypes of clear cell renal cell carcinomas. Clin Cancer Res. 2013;19:2460-72.

5. Belleudi F, Purpura V, Torrisi MR. The receptor tyrosine kinase FGFR2b/KGFR controls early differentiation of human keratinocytes. PLoS One. 2011;6: e24194.

6. Purpura V, Belleudi F, Caputo S, Torrisi MR. HPV16 E5 and KGFR/ FGFR2b interplay in differentiating epithelial cells. Oncotarget. 2013;4:192-205.

7. Rosato B, Ranieri D, Nanni M, Torrisi MR, Belleudi F. Role of FGFR2b expression and signaling in keratinocyte differentiation: sequential involvement of PKC $\delta$ and PKCa. Cell Death Dis. 2018:9:565.

8. Ranieri D, Rosato B, Nanni M, Belleudi F, Torrisi MR. Expression of the FGFR2C mesenchymal splicing variant in human keratinocytes inhibits differentiation and promotes invasion. Mol Carcinog. 2018;57:272-83.

9. Ranieri D, Belleudi F, Magenta A, Torrisi MR. HPV16 E5 expression induces switching from FGFR2b to FGFR2c and epithelial-mesenchymal transition. Int J Cancer. 2015;137:61-72.

10. Ranieri D, Rosato B, Nanni M, Magenta M, Belleudi F, Torrisi MR. Expression of the FGFR2 mesenchymal splicing variant in epithelial cells drives epithelial-mesenchymal transition. Oncotarget. 2016;7:5440-60.

11. Nanni M, Ranieri D, Persechino F, Torrisi MR, Belleudi F. The aberrant expression of the mesenchymal variant of FGFR2 in the epithelial context inhibits autophagy. Cells. 2019;8:653-74. 
12. Gorin MA, Pan Q. Protein kinase C epsilon: an oncogene and emerging tumor biomarker. Mol Cancer. 2009;8:9.

13. Isakov N. Protein kinase C (PKC) isoforms in cancer, tumor promotion and tumor suppression. Semin Cancer Biol. 2018;48:36-52.

14. Jain K, Basu A. Protein kinase $C-\varepsilon$ promotes EMT in breast cancer. Breast Cancer (Auckl). 2014:8:61-7.

15. Jain K, Basu A. The multifunctional protein kinase $C-\varepsilon$ in cancer development and progression. Cancers (Basel). 2014;6:860-78.

16. Papp G, Czifra E, Bodó J, Lázár I, Kovács M, Aleksza I, et al. Opposite roles of protein kinase $\mathrm{C}$ isoforms in proliferation, differentiation, apoptosis, and tumorigenicity of human HaCaT keratinocytes. Cell Mol Life Sci. 2004;61: 1095-105.

17. Lau E, Kluger H, Varsano T, Lee KY, Scheffler I, Rimm DL, et al. PKC $\varepsilon$ promotes oncogenic functions of ATF2 in the nucleus while blocking its apoptotic function at mitochondria. Cell. 2012;148:543-55.

18. Karavana VN, Gakiopoulou H, Lianos EA. Expression of Ser729 phosphorylated PKCepsilon in experimental crescentic glomerulonephritis: an immunohistochemical study. Eur J Histochem. 2014;58:2308.

19. Zhang L, Keane MP, Zhu LX, Sharma S, Rozengurt E, Strieter RM, et al. Interleukin-7 and transforming growth factor-beta play counter-regulatory roles in protein kinase C-delta-dependent control of fibroblast collagen synthesis in pulmonary fibrosis. J Biol Chem. 2004;279:28315-9.

20. Thiery JP, Acloque H, Huang RY, Nieto MA. Epithelial- mesenchymal transitions in development and disease. Cell. 2009;139:871-90.

21. Lamouille S, Xu J, Derynck R. Molecular mechanisms of epithelialmesenchymal transition. Nat Rev Mol Cell Biol. 2014;15:178-96.

22. Tran DD, Corsa CA, Biswas H, Aft RL, Longmore GD. Temporal and spatial cooperation of Snail1 and Twist1 during epithelial-Mesenchymal transition predicts for human breast cancer recurrence. Mol Cancer Res. 2011;9:164457.

23. Chan KS, Sano S, Kiguchi K, Anders J, Komazawa N, Takeda J, et al Disruption of Stat3 reveals a critical role in both the initiation and the promotion stages of epithelial carcinogenesis. J Clin Invest. 2004;114:720-8.

24. Alvarez JV, Febbo PG, Ramaswamy S, Loda M, Richardson A, Frank DA. Identification of a genetic signature of activated signal transducer and activator of transcription 3 in human tumors. Cancer Res. 2005;65:5054-62.

25. Rivat C, Rodrigues S, Bruyneel E, Piétu G, Robert A, Redeuilh G, et al. Implication of STAT3 signaling in human colonic cancer cells during intestinal trefoil factor 3 (TFF3) — and vascular endothelial growth factormediated cellular invasion and tumor growth. Cancer Res. 2005;65:195-202.

26. Aziz MH, Manoharan HT, Church DR, Dreckschmidt NE, Zhong W, Oberley TD, et al. Protein kinase Cepsilon interacts with signal transducers and activators of transcription 3 (Stat3), phosphorylates Stat3Ser727, and regulates its constitutive activation in prostate cancer. Cancer Res. 2007;67: 8828-38.

27. Kobielak A, Fuchs E. Links between a-catenin, NF- nB, and squamous cell carcinoma in skin. Proc Natl Acad Sci U S A. 2006;103:2322-7.

28. Aziz MH, Manoharan HT, Verma AK. Protein kinase C epsilon, which sensitizes skin to sun's UV radiation-induced cutaneous damage and development of squamous cell carcinomas, associates with Stat3. Cancer Res. 2007:67:1385-94.

29. Dudka AA, Sweet SM, Heath JK. Signal transducers and activators of transcription-3 binding to the fibroblast growth factor receptor is activated by receptor amplification. Cancer Res. 2010;70:3391-401.

30. Tam WL, Lu H, Buikhuisen J, Soh BS, Lim E, Reinhardt F, et al. Protein kinase $\mathrm{C}$ a is a central signaling node and therapeutic target for breast cancer stem cells. Cancer Cell. 2013;24:347-64.

31. Mathur A, Ware C, Davis L, Gazdar A, Pan BS, Lutterbach B. FGFR2 is amplified in the $\mathrm{NCl}-\mathrm{H} 716$ colorectal cancer cell line and is required for growth and survival. PLoS One. 2014;9:e98515.

32. Warzecha CC, Sato TK, Nabet B, Hogenesch JB, Carstens RP. ESRP1 and ESRP2 are epithelial cell-type-specific regulators of FGFR2 splicing. Mol Cell. 2009:33:591-601.

33. Ishiwata T. Role of fibroblast growth factor receptor-2 splicing in normal and cancer cells. Front Biosci. 2018;23:626-39.

34. Latko M, Czyrek A, Porębska N, Kucińska M, Otlewski J, Zakrzewska M, et al. Cross-talk between fibroblast growth factor receptors and other cell surface proteins. Cells. 2019:8:455-83.

35. Rosse C, et al. PKC and the control of localized signal dynamics. Nat Rev Mol Cell Biol. 2010:11:103-12.
36. Newton PM, Messing RO. The substrates and binding partners of protein kinase Cepsilon. Biochem J. 2010;427:189-96.

\section{Publisher's Note}

Springer Nature remains neutral with regard to jurisdictional claims in published maps and institutional affiliations.

\section{Ready to submit your research? Choose BMC and benefit from:}

- fast, convenient online submission

- thorough peer review by experienced researchers in your field

- rapid publication on acceptance

- support for research data, including large and complex data types

- gold Open Access which fosters wider collaboration and increased citations

- maximum visibility for your research: over $100 \mathrm{M}$ website views per year

At BMC, research is always in progress.

Learn more biomedcentral.com/submissions 